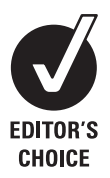

- Additional appendices are published online only at http:// oem.bmi.com/content/vol65/ issueg

${ }^{1}$ School of Environmental Health, The University of British Columbia, Vancouver, BC, Canada; ${ }^{2}$ Department of Health Care and Epidemiology, The University of British Columbia, Vancouver, BC, Canada

Correspondence to: Elizabeth Nethery, School of Environmental Health, The University of British Columbia, 3rd Floor, 2206 East Mall, Vancouver, BC, Canada V6T 1Z3; enethery@interchange.ubc.ca

Accepted 22 November 2007 Published Online First 10 December 2007

\title{
From measures to models: an evaluation of air pollution exposure assessment for epidemiological studies of pregnant women
}

\author{
E Nethery, ${ }^{1}$ S E Leckie, ${ }^{1}$ K Teschke, ${ }^{1,2}$ M Brauer ${ }^{1}$
}

\begin{abstract}
Objectives: To evaluate exposure estimation methods such as spatially resolved land-use regression models and ambient monitoring data in the context of epidemiological studies of the impact of air pollution on pregnancy outcomes.
\end{abstract}

Methods: The study measured personal $48 \mathrm{~h}$ exposures (NO, $\mathrm{NO}_{2}, \mathrm{PM}_{2.5}$ mass and absorbance) and mobility (time activity and GPS) for 62 pregnant women during 2005-2006 in Vancouver, Canada, one to three times during pregnancy. Measurements were compared to modelled (using land-use regression and interpolation of ambient monitors) outdoor concentrations at subjects' home and work locations.

Results: Personal NO and absorbance (ABS) measurements were moderately correlated (NO: $r=0.54$, ABS: $r=0.29$ ) with monitor interpolations and explained primarily within-subject (temporal) variability. Land-use regression estimates including work location improved correlations for NO over those based on home postal code (for NO: $r=0.49$ changed to NO: $r=0.55$ ) and explained more between-subject variance (4-20\%); limiting to a subset of samples $(n=61)$ when subjects spent $>65 \%$ time at home also improved correlations (NO: $r=0.72$ ). Limitations of the GPS equipment precluded assessment of including complete GPS-based mobility information. Conclusions: The study found moderate agreement between short-term personal measurements and estimates of ambient air pollution at home based on interpolation of ambient monitors and land-use regression. These results support the use of land-use regression models in epidemiological studies, as the ability of such models to characterise high resolution spatial variability is "reflected" in personal exposure measurements, especially when mobility is characterised.

A growing body of epidemiological research indicates adverse effects of outdoor air pollution on birth outcomes, ${ }^{12}$ such as low birth weight, preterm birth and intrauterine growth retardation. Studies of birth outcomes have used different methods to estimate exposure, including nearest monitor, ${ }^{3}$ interpolation ${ }^{4}$ and traffic-based metrics, ${ }^{5}$ or, for small study populations, short-term personal sampling. ${ }^{67}$ Various studies have reported associations between modelled estimates of traffic-related air pollution and adverse birth outcomes, ${ }^{58}$ but these models have not yet been evaluated.

Spatial variability in air pollutant concentrations between cities, ${ }^{910}$ between urban and rural areas, ${ }^{11}$ and within cities $^{12}$ has been demonstrated. Recent epidemiological studies have identified the importance of capturing within-city spatial variability in air pollution exposure. ${ }^{13}{ }^{14}$ Specifically, studies of traffic-related air pollution have used proximity (ie, living near a busy road), ${ }^{15}$ traffic volume or density measures ${ }^{5}{ }^{16}$ or land-use regression (LUR) ${ }^{17}$ models as exposure indicators. LUR models use a combination of outdoor measurements and geographical variables to estimate within-city variations in traffic-related air pollution. ${ }^{18} 19$ Generally, traffic-related air pollution exposure indicators incorporate little or no temporal variability and are used to assess impacts of chronic exposures. A few evaluations of "living near a busy road" 20 or traffic density and urbanisation measures, ${ }^{21}$ as indicators of personal exposure in children, demonstrated contrasts in personal exposure using these metrics. No published studies have evaluated LUR estimates of exposure against personal measurements. A recent evaluation of the use of a small number of ambient monitors to predict population exposure to air pollution in France showed little association between ambient monitors and personal measurements. ${ }^{22-24}$ These authors called for caution in using monitor-based approaches in epidemiological studies of long-term exposure (those exploiting spatial contrasts). ${ }^{22-24}$

In evaluating air pollution exposure assessment methods for epidemiological studies we suggest some key questions: First, how well do exposure models estimate personal exposure? Secondly, can the ability of models to account for spatial effects be improved by including personal mobility data if available? For example, although people spend 60 $80 \%$ of their time at and/or near home,$^{25}$ including subject-level mobility, such as time spent at work or in transit, could improve exposure assessments. ${ }^{26}{ }^{27}$ Thirdly, how well do models account for temporal variability (ie, changes in ambient concentrations over time)? Depending on the health effect being studied, either spatial or temporal precision may be particularly important for detecting associations. Air pollution exposure assessment methods commonly used in large epidemiological cohort studies have rarely been evaluated against personal sampling. Accordingly, we collected short-term personal air pollutant measurements and mobility data for a sample of pregnant women and compared these to their modelled concentrations using interpolated ambient monitoring data and LUR models. Using repeated samples per subject, we examined two intermediate term (monthly) exposure models ability to predict measured short-term exposures. We attempted to compare the models' abilities to 
predict the spatial and temporal components affecting measured personal exposures.

\section{METHODS}

\section{Study subjects}

We studied a sample of 62 pregnant women living in the central Vancouver metropolitan area in 2005-2006 (population of 1.3 million over $1500 \mathrm{~km}^{2}$ ). Vancouver benefits from a temperate climate year round, has a relatively healthy and active population, low smoking rates $(15 \%$ across the province of British Colombia) and high incomes (2003 average income per tax-filer was $C \$ 47000$ per year). The inclusion criteria were women who self-reported as healthy and experiencing low-risk pregnancies and non-smokers living with non-smokers. We recruited through prenatal classes, word-of-mouth and posters. The study protocol and material were approved by the University of British Columbia Behavioural Research Ethics Board (\#B05-0441).

\section{Exposure measurement and estimation}

For each study subject, we generated estimates of exposure to ambient nitric oxide (NO), nitrogen dioxide $\left(\mathrm{NO}_{2}\right)$, fine particulate $\left(\mathrm{PM}_{2.5}\right)$ mass and filter absorbance, using three approaches: (1) personal sampling, (2) interpolated ambient monitoring measurements and (3) previously developed LUR models. $^{28}$

\section{Personal exposure measurements and activity recording}

Each woman carried personal air monitoring equipment and a global positioning system (GPS) datalogger in a small backpack or shoulder bag (with the air monitors attached to the shoulder strap in the breathing zone), and completed a self-administered time-activity diary during each $48 \mathrm{~h}$ sampling session. Subjects completed one to three sampling sessions each (one per trimester); most were in their second trimester when recruited, and thus completed only two sampling sessions. In total, there were 127 sampling days with one to four subjects monitored per day; sampling was conducted from September 2005 to August 2006.

We measured personal fine particles with personal environment monitors (PEM) (MSP, Shoreview, MN, USA). The PEM was loaded with a pre-weighed $37 \mathrm{~mm}$ Teflon filter (Pall, East Hills, NY) connected to a battery-powered sampling pump (Leland Legacy, SKC, Eighty Four, PA) set to 51 /min flow rate. This flow rate, resulting in a $50 \%$ cut point of $2.2 \mu \mathrm{m}$, was used to collect a sample more representative of traffic-combustion generated fine particles. Triplicate mass measurements were made in a temperature $\left(23^{\circ} \mathrm{C}\left(\mathrm{SD} 0.77^{\circ} \mathrm{C}\right)\right.$ ) and humiditycontrolled (34\% (SD 3\%)) weighing room as described previously. ${ }^{29}$ The limit of detection, calculated as three times the standard deviation of the laboratory blanks, was $1 \mu \mathrm{g} / \mathrm{m}^{3}$ based on a $48 \mathrm{~h}$ sample.

After weighing, we measured the reflectance of each filter (Smoke Stain Reflectometer, Diffusion Systems, London, UK) and calculated the absorbance (SOP ULTRA/KTL-L-1.0). ${ }^{30} \mathrm{NO}$ and $\mathrm{NO}_{2}$ were sampled with Ogawa passive samplers (Ogawa, Pompano Beach, FL) and analysed by ion chromatography. Duplicate sampling indicated a precision of $5 \%$ for $\mathrm{NO}$ and $\mathrm{NO}_{2}$ measurements by the Ogawa badges. Limits of detection were $0.1 \times 10^{-5} \mathrm{~m}^{-1}$ for absorbance, $8.8 \mathrm{ppb}$ for $\mathrm{NO}$ and $4.5 \mathrm{ppb}$ for $\mathrm{NO}_{2}$.

GPS dataloggers (BlueLogger, DeLorme, Yarmouth, ME) fitted with a long-life battery pack (Alti-tech, Vancouver, Canada) recorded latitude, longitude, time and speed every $5 \mathrm{~s}$ while a GPS signal was detected (manufacturers' reported accuracy $\pm 20 \mathrm{~m}$ with full signal). We verified the GPS signal at the start of each session but did not ask subjects to check the signal during the session to avoid overburdening them and to reduce potential bias. We also wanted to evaluate the technology's application in exposure studies when participants were specifically instructed to ignore the equipment.

In the activity diary, subjects recorded their locations (indoors at home/work/other, outdoors, or in transit) at $0.5 \mathrm{~h}$ intervals and we calculated the percentage of time each subject spent in each microenvironment. For GPS route data, points within $350 \mathrm{~m}$ of home and $400 \mathrm{~m}$ of work were identified, and we calculated percentages of time spent at home and at work from these data.

\section{Geocoding addresses and postal codes}

Generally, only postal codes are available in population-based epidemiology studies due to privacy concerns. Therefore, for each subject, we geocoded the home and work address, as well as the postal code centroid, using ArcGIS/ArcMap v 9.1 (ESRI, Redlands, CA, USA), the CanMap Streetfiles, 2001 (DMTI Spatial, Markham, Canada) road network and CanMap Multiple Enhanced Postals (DMTI Spatial). In Canadian urban areas, postal codes can represent an area as small as an apartment building or a block face. Since geocoding may mislocate addresses for large building footprints, we obtained land parcel data (lot boundaries and addresses) from the municipalities (2004-2005) in the study area and combined these with attribute data from BC Property Assessment. ${ }^{31}$ All address points were adjusted to the centre of the street-facing portion of their respective land parcels.

\section{Exposure estimates using ambient monitoring data}

We extracted hourly $\mathrm{PM}_{2.5}, \mathrm{NO}$ and $\mathrm{NO}_{2}$ measurements from all ambient monitoring stations within $50 \mathrm{~km}$ of the subjects' homes (11 stations for $\mathrm{NO} / \mathrm{NO}_{2}$, six stations for $\mathrm{PM}_{2.5}$ ). All stations used consistent methods: chemiluminescence for $\mathrm{NO} /$ $\mathrm{NO}_{2}$ and TEOMs for $\mathrm{PM}_{2.5}{ }^{32}$ We assigned ambient monitor data to subjects' home postal codes using: (1) values from the nearest station and (2) an inverse distance weighted (IDW) interpolation $\left(1 /\right.$ distance $\left.^{2}\right)$ of the nearest three stations. Measurements were averaged for the 14 days before and after the personal sampling to generate a "monthly" estimate (table 1). Spatio-temporal comparisons and visual representations of LUR and ambient monitor methods for this study area are reported elsewhere. ${ }^{33}$

\section{Exposure estimates using LUR models}

The LUR models ${ }^{28}$ generate raster (continuous) surfaces $(10 \times 10 \mathrm{~m}$ resolution) covering the whole of the Greater Vancouver Regional District. Briefly, the models were based on a saturation sampling campaign (112 locations for $\mathrm{NO}, \mathrm{NO}_{2}$; 25 locations for $\mathrm{PM}_{2.5}$ mass and absorbance). Geographical predictors representing road density, land use, population, elevation and traffic density were used in regression models to predict measured concentrations and generate surfaces from which estimates of concentration at any location in the study area could be obtained. The models used in this study were based on measures of road length and population density. $\mathrm{R}^{2}$ values for the models (using geographical predictors) were 0.62 (NO), $0.56\left(\mathrm{NO}_{2}\right), 0.52\left(\mathrm{PM}_{2.5}\right)$ and 0.39 (absorbance) and validation $\mathrm{R}^{2}$ values (comparisons to independent monitors at 
Table 1 Exposure estimation methods used in this analysis and their spatial and temporal averaging scales

\begin{tabular}{|c|c|c|}
\hline Exposure estimation method & Temporal averaging & Spatial averaging \\
\hline Personal measurements & $48 \mathrm{~h}$ & Integrated sample over all locations for the subject when the sample was collected \\
\hline LUR: home & Monthly*, annual & $\begin{array}{l}\text { Average for subjects' home postal code location based on LUR (has about a } 50 \mathrm{~m} \text { spatia } \\
\text { resolution) }\end{array}$ \\
\hline LUR: home+work & Monthly, annual & $\begin{array}{l}\text { Time-weighted average of home and work postal code locations based on LUR (has } \\
\text { about a } 50 \text { m spatial resolution) }\end{array}$ \\
\hline Ambient monitors (nearest monitor) & Monthly, $48 \mathrm{~h} \dagger$ & Distance to nearest monitoring stations (about $10 \mathrm{~km}$ on average) \\
\hline Ambient monitors (inverse distance weighting) & Monthly, $48 \mathrm{~h} \dagger$ & $\begin{array}{l}\text { Average of } 3 \text { nearest monitoring stations, weighted by distance - gives a spatial } \\
\text { resolution that varies with monitor density }\end{array}$ \\
\hline
\end{tabular}

*No monthly averaging for absorbance; †ambient $48 \mathrm{~h}$ results not shown; described as sensitivity analysis in the Discussion.

LUR, land-use regression.

16 sites for $\mathrm{NO} / \mathrm{NO}_{2}$ and eight sites $\mathrm{PM}_{2.5}$ ) were 0.49 (NO), 0.69 $\left(\mathrm{NO}_{2}\right)$ AND $0.09\left(\mathrm{PM}_{2.5}\right)$. The surfaces were smoothed to decrease the resolution to $30 \times 30 \mathrm{~m}$ to avoid small errors in geocoding resulting in large numerical changes in exposure estimates.

A unique feature of these models was the addition of ambient monitoring network data from 1998-2004 to generate adjustment factors for monthly temporal variation. These adjustment factors assume that the spatial pollution patterns remained the same, and raised or lowered the entire model surface relative to an annual average. These monthly adjustment factors were applied to the model surfaces, therefore generating LUR exposure estimates for this study that corresponded to the same month as the personal samples, for each subject-sampling session combination. Both annual and monthly-adjusted surfaces were used for all pollutants except "absorbance" (no monthly trend was applied, by design, because ambient absorbance did not vary consistently by season) (table 1).

We also incorporated "mobility" indicators into the LUR model estimates in this study, using the time-activity and GPS route data. Thus, we generated LUR exposure estimates based on home location only (ie, assuming the subject spent $100 \%$ of time at home), home+work locations (weighted by the percentage of time spent at home and work from the participants' time-activity diary, assuming that the home and work time summed to $100 \%$ ), and estimates based on the detailed GPS route data (taking into account the full range of locations for each participant during a sampling session). This last was done by extracting the LUR model values for every GPS route point and then averaging the time-weighted estimates for every GPS point in a route. This approach reflects all of the subjects' mobility during their sampling session and was used only for sampling sessions with "complete" GPS route data ( $\mathrm{n}=35)$. To determine "complete routes", we calculated time gaps between each GPS point (average signal precision was $\pm 30 \mathrm{~m}$ when signal was established). Routes were excluded if there were large time gaps $(>16 \mathrm{~h})$ or a combination of space and time gaps between points.

Two sets of home and home+work estimates were generated: one based on address location and the other based on postal codes.

\section{Statistical analysis}

Data were analysed using SAS-PC v 9.1 (SAS Institute, Cary, NC). All personal measurements were compared against modelled estimates using Pearson's $r$ correlations. We also created linear regression models for each pollutant with personal exposure (log-transformed) as the dependent variable, using mixed effects models, to examine the ability of exposure estimates to explain different components of the variability (between- and within-subject) in personal measurements, while controlling for repeated measures among subjects.

\section{RESULTS}

Of the 62 women in the study, 55 completed two samples and, of those, 10 completed three samples. Subjects with only one sample ( $\mathrm{n}=7$; due to miscarriage, early delivery, moving out of the study area or withdrawal from study) were still included in the analysis. Subjects were primarily white (82\%), with a mean age of 32 years, highly educated ( $90 \%$ university educated) and with a median family income of C\$60 000-80 000 per year. A total of 127 samples were collected between October 2005 and August 2006 (31\% in winter, 39\% in spring, 17\% in summer and $13 \%$ in fall). The mean distance from participants' home to work was $6.3 \mathrm{~km}$ (range $0.7-21 \mathrm{~km}$ ). There were 13 women who worked from home or did not work.

Since LUR exposure estimates based upon addresses were very highly correlated with those based upon postal code estimates for all pollutants (home: Pearson's $\mathrm{r}=0.90-0.96$; work: Pearson's $r=0.87-0.97)$, only postal code results are presented. Postal code information is more commonly available for population-based cohorts. Not surprisingly, given monitor density and $1 /$ distance $^{2}$ weighting, estimates based on the nearest ambient monitor were very similar to those based on inverse distance weighting (IDW); therefore results are reported for IDW only.

Personal exposure measurements were higher and more variable (table 2) than LUR or ambient monitor (IDW) exposure estimates. LUR estimates had greater variability and covered a wider range compared to the monitor-based estimates. This is expected for several reasons: LUR incorporates higher spatial resolution, monitor-based estimates are constrained by the range of the (relatively few) monitoring sites, and the monitorbased sites are primarily urban background sites which will suppress some variability.

For the 35 samples with complete GPS route data, the percentage of time calculated to have been spent at home and work was highly correlated with percentage estimates based on activity logs (home: $r=0.96$; work: $r=0.88$ ). Six participants worked at home but coded their activities as "work", which may account for the observed lower correlation for work activities. Similarly, for this same subset, mobility-adjusted LUR exposure estimates (using full GPS route data) were highly correlated with home-only estimates $(r=0.83-0.92)$ and very highly correlated with the home+work estimates $(r=0.94-0.98)$ for all pollutants.

Figure 1 shows scatter plots and simple correlations between personal monitoring results and each of the following exposure estimates: estimates based on ambient monitors (monthly, with inverse distance weighting) and LUR (home-based estimates). 
Table 2 Exposure estimates based on personal sampling, land-use regression and ambient monitors

\begin{tabular}{|c|c|c|c|c|c|}
\hline Estimated exposure & Method & Arithmetic mean (SD) & Geometric mean (GSD) & Min-Max & IOR \\
\hline NO (ppb), & Personal sampling* & $48.5(50.5)$ & $36.7(2.0)$ & $6.9-474$ & 37.5 \\
\hline \multirow[t]{2}{*}{$\mathrm{n}=127$} & LUR† home (monthly) & $27.0(19.7)$ & $21.4(2.0)$ & $3.6-146$ & 25.5 \\
\hline & LUR home+work (monthly) & $28.0(18.4)$ & $23.2(1.9)$ & $6.0-134$ & 24.7 \\
\hline $\mathrm{NO}_{2}(\mathrm{ppb})$, & Personal sampling & $18.7(9.2)$ & $16.9(1.6)$ & $4.8-76$ & 11.1 \\
\hline \multirow[t]{2}{*}{$\mathrm{n}=127$} & LUR home (annual)§ & $17.3(3.3)$ & $16.9(1.2)$ & $6.5-28$ & 2.8 \\
\hline & LUR home+work (annual) & $17.4(2.9)$ & $17.2(1.2)$ & $7.6-27$ & 2.5 \\
\hline \multirow[t]{3}{*}{$n=120$} & LUR home (annual) & $0.7(0.3)$ & $0.7(1.7)$ & $0.0-1.2$ & 0.2 \\
\hline & LUR home+work (annual) & $0.7(0.2)$ & $0.7(1.7)$ & $0.1-1.3$ & 0.2 \\
\hline & No monitor data & & & & \\
\hline $\mathrm{PM}_{2.5}\left(\mu \mathrm{g} / \mathrm{m}^{3}\right)$ & Personal sampling ${ }^{* *}$ & $11.3(6.6)$ & $10.0(1.6)$ & $4.2-45.3$ & 5.7 \\
\hline$n=124$ & LUR home (annual) & $4.2(1.5)$ & $4.2(1.4)$ & $0.0-10.1$ & 1.5 \\
\hline
\end{tabular}

*One NO personal sample was below the limit of detection (LOD). All other samples were above their respective LODs.

HLUR surfaces as described in Henderson et $a^{28}$ and that were developed based on road length metrics.

HIDW concentrations from the three closest monitoring stations.

§In the analyses, annual $\mathrm{NO}_{2}$ showed the strongest relationship to personal measurements (rather than monthly), so only annual results are reported in the descriptive tables.

TNo monthly trend was applied to the absorbance estimates by design in the development of the LUR surface for this pollutant.

** Personal sampling for particulate was collected as $\mathrm{PM}_{2.2}$ not $\mathrm{PM}_{2.5}$; for simplicity, all tables and figures will refer to $\mathrm{PM}{ }_{2.5}$ for all fine particulate sampling.

ABS, absorbance; IDW, inverse distance weighted; IQR, interquartile range; LUR, land-use regression.

Only NO demonstrated moderate correlations using all approaches to exposure estimation.

\section{Mobility effects}

LUR exposure estimates using home and work locations (table 3) were slightly more highly correlated with personal measurements for $\mathrm{NO}(\mathrm{r}=0.55)$ and $\mathrm{NO}_{2}(\mathrm{r}=0.28)$ than using only home location. For the subset of data with full GPS routes (table 3), using route-based (GPS) LUR estimates showed only slight improvement over the home+work estimates when compared to personal measurements (NO: home+work $r=0.77$, GPS $r=0.78 ; \quad \mathrm{NO}_{2}$ : home+work $r=0.57$, GPS $\mathrm{r}=0.66$; absorbance: not significant; $\mathrm{PM}_{2.5}$ : home+work $r=0.45$; GPS $r=0.47$ ). The correlations were stronger for all pollutants when analysing only the subjects with complete GPS data. However, we noted that on sampling sessions with complete GPS route data, subjects spent significantly more time at home than on the sessions with incomplete GPS route data. When stratifying to subjects who spent more time at home $(>65 \%)$, the LUR and monitor-based estimates were more strongly correlated with the personal measurements than when using all samples (eg, for NO home LUR: $r=0.72$, NO monitors: $r=0.59)$. The normalised root mean squared errors (NRMSE) show similar trends across the pollutants, the lowest error (7$10 \%$ ) for $\mathrm{NO}$ indicating the trends are strongest for this pollutant. Higher NRMSEs when stratified by mobility are likely due to smaller sample sizes. As the data were logtransformed for analysis, we converted the residuals to the untransformed domain before calculating the RMSEs and normalised the results using the true measurement range thus giving the NRMSE (a percentage) for ease of interpretation.

The mixed-effects regression results (table 4) show the proportion of variability in personal measurements explained by the various exposure estimate "predictors". If an exposure estimate explains some of the variability in the personal measurements, a reduction in the variance component is expected, compared to a model with no exposure predictors (baseline model). The within-subject variance reflects differences in exposures measured on the subject's repeated samples, differences expected to be dominated by temporal changes in ambient pollution but also affected by variations in subjects' mobility or the impact of indoor sources between sampling days. The between-subject variance we expect to be dominated by spatial differences in pollution. In table 4 , the within-subject variance component for $\mathrm{NO}$ showed little change with different exposure estimates. Since both estimates include the same temporal trends but different spatial characteristics, we conclude that this within-subject variance is dominated by temporal changes in ambient concentrations. For between-subject variance, more variance is explained for $\mathrm{NO}$ when work location is incorporated (from 4\% to 20\%), which supports the hypothesis that this variance is dominated by spatial effects.

Overall, the variance components show similar patterns to the correlations but inform us about how the exposure estimate contributes to predicting the variability in personal data. An increase in within-subject variance suggests that temporal effects are important, whereas an increase in between-subject effects suggests importance of spatial components. The LUR approaches are intended to detect intra-urban spatial differences in exposure, so improving our estimates spatially (ie, by including work location) should increase the ability of the LUR model to predict between-subject differences. In the case of $\mathrm{NO}$ and (weakly) $\mathrm{NO}_{2}$, we observed an increase in variance explained by the LUR model with a more spatially refined estimate. The results for absorbance and $\mathrm{PM}_{2.5}$ show that the weak correlation (fig 1) of the personal measurements with ambient monitoring data was dominated by within-subject effects likely caused by temporal shifts in ambient pollution. In addition, for these pollutants the between-subject variance was small overall, likely from the low intra-urban spatial variability in concentrations.

The fixed-effect (slope) values from the regression models in table 4 describe a predicted change in the personal sample (dependent) for a change in the exposure estimate (independent) adjusted to the interquartile range (IOR) of that independent variable. These values (table 5 in the online 


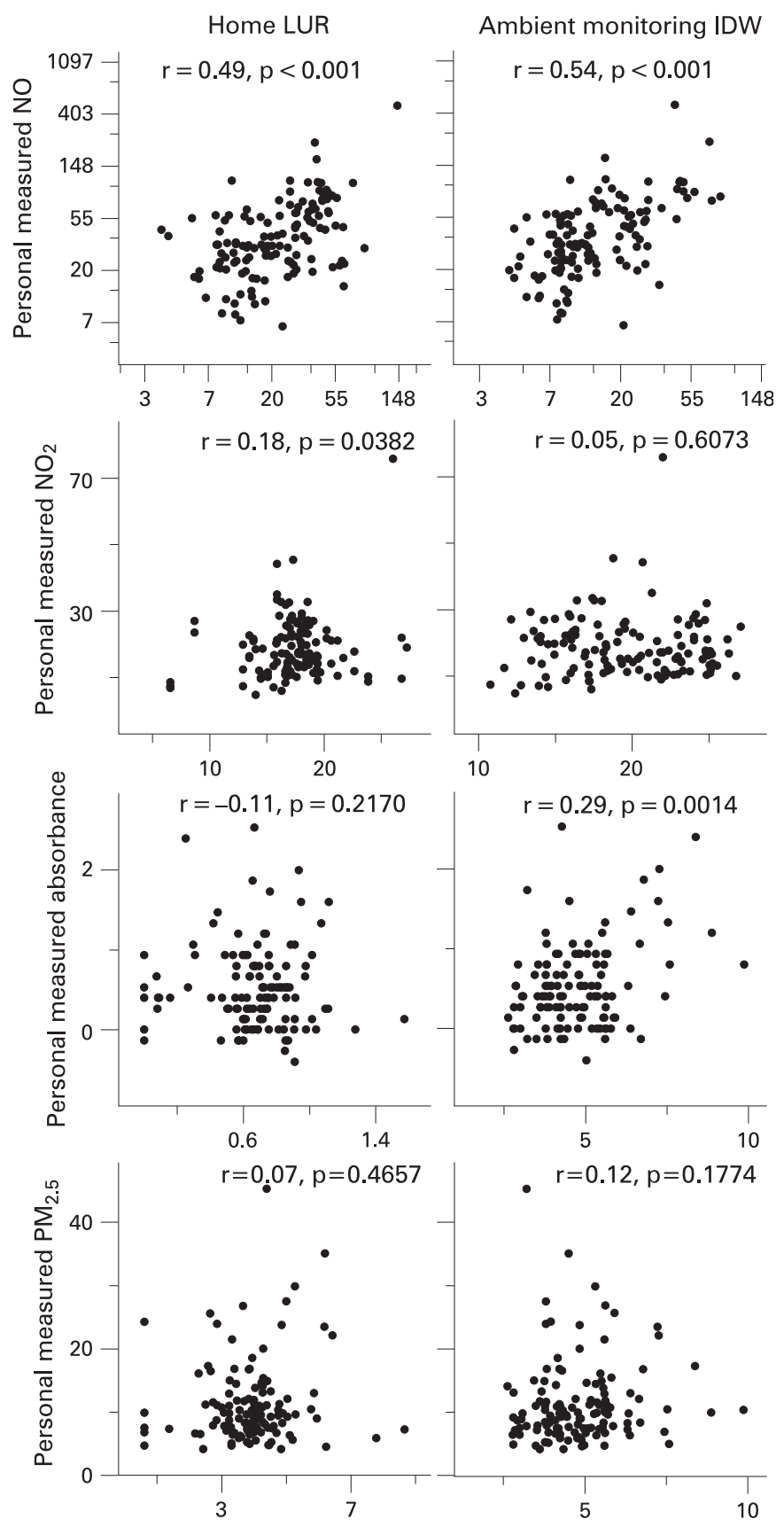

Figure 1 Scatter plots and Pearson's $r$ correlations (and $p$ values) for comparisons between personal measurements $(n=127)$ and exposure estimates using land-use regression (LUR) and ambient monitoring stations inverse distance weighted.

appendix, see supplementary data) are reported as a percentage increase (due to the log-transformation of the dependent variable): for NO, 61\% increase with an IOR increase in LUR and $41 \%$ increase with an IOR increase in monitor-based estimates (IDW). There was a marginal increase in slope using NO LUR home+work compared to home alone, suggesting that controlling for mobility increased our ability to predict personal exposure using outdoor LUR modelled NO.

\section{Comparing pollutants}

Overall, NO models performed best at explaining the spatial (between-subject) variability in personal exposure in this population. For $\mathrm{NO}_{2}$, annual LUR estimates explained a modest amount of the spatial variability only. In comparing the ability of ambient monitors to predict personal measurements for different pollutants, $\mathrm{NO}$ explained more of the between-subject variance than $\mathrm{PM}_{2.5}$ (table 3) or absorbance; $\mathrm{NO}_{2}$ was not at all associated.

\section{DISCUSSION}

This study is the first to evaluate LUR models as predictors of personal exposure in any study population. The unique focus on personal exposures of pregnant women has also increased exposure data for this potentially vulnerable population. We found that LUR models showed the strongest ability to predict personal measures for some pollutants $\left(\mathrm{NO}\right.$ and $\mathrm{NO}_{2}$ ), while ambient monitor estimates were also predictive in some cases (NO, absorbance, $\mathrm{PM}_{2.5}$ ). Including mobility, based on work location, improved exposure models.

\section{Evaluation of LUR estimates}

Focusing on LUR, we saw moderate correlations and an increasing slope based on the fixed effect estimates from regression models where we controlled for repeated measures among subjects. For $\mathrm{NO}_{2}$, only annual average LUR values were modestly associated with personal results. While both the NO and $\mathrm{NO}_{2}$ models were developed using the same number of samples and have similar $\mathrm{R}^{2}$ values, only $\mathrm{NO}$ showed a strong relationship with personal measurements in this study. Considering only the annual LUR values, NO had much greater spatial variability (higher $\mathrm{SD}$ ) than $\mathrm{NO}_{2}$. The surfaces also show less distinct spatial variation for $\mathrm{NO}_{2}$ than $\mathrm{NO}$ (less transitions in colour/shading). ${ }^{28}{ }^{33}$ This result was expected, given that $\mathrm{NO}_{2}$ requires atmospheric transformation, whereas $\mathrm{NO}$ is a primary emission. We suspect that the $\mathrm{NO}_{2}$ signal from traffic is obscured by the effects of indoor sources and its lower spatial variability relative to $\mathrm{NO}$.

We saw little relationship between personal measurements and LUR estimates for particulate pollutants (absorbance, $\mathrm{PM}_{2.5}$ ), likely because of the low spatial variability of these pollutants in our area, ${ }^{29}$ the fewer sites (compared to $\mathrm{NO} / \mathrm{NO}_{2}$ ) sampled when developing LUR models, and the resulting lower LUR model and validation $R^{2}$ values. ${ }^{28}$

\section{Evaluation of spatial proximity to roads}

Several studies have also demonstrated that differences in traffic intensity and/or living near a busy road can be correlated with personal measurements ( $\mathrm{NO}, \mathrm{NO}_{2}$ and/or absorbance). Van Roosbroeck et $a^{20}$ found an increase of $77 \%$ (unadjusted for indoor sources) in home outdoor $\mathrm{NO}$ (but no significant increase for $\mathrm{NO}_{2}$ ) and $38 \%$ in personal absorbance for children living near a busy road (within 75 m of road with 10000 cars/ day) in a study of 40 children in the Netherlands compared to children living at urban background locations. In our study, we found small and non-significant increases in arithmetic means for $\mathrm{NO}$ (47.2 vs $53.3 \mathrm{ppb}$ ) and $\mathrm{NO}_{2}$ (18.2 vs $20.7 \mathrm{ppb}$ ) for subjects living within $75 \mathrm{~m}$ of a road with 15000 cars/day compared to the rest of the study population. Our inability to detect a strong proximity effect may be due to the relatively few subjects $(n=15)$ living close to busy roads. In addition, distance to road was confounded by building type; high-rise or large multi-unit buildings were on average $150 \mathrm{~m}$ closer to busy roads than smaller buildings $(p=0.003)$. Similarly, those living more than four floors above ground were also closer to busy roads and higher elevations around high-rise buildings can result in lower concentrations. ${ }^{34}$ 
Table 3 Correlations and normalised root mean squared error (NRMSE)* between personal measurements and exposure estimates (same pollutant, except absorbance as noted) for all subjects and subset with $>$ and $\leqslant 65 \%$ of time spent at home

\begin{tabular}{|c|c|c|c|c|}
\hline \multirow{2}{*}{$\begin{array}{l}\text { Personal measurements (log-transformed) } \\
\text { compared to modelled concentrations }\end{array}$} & \multicolumn{4}{|c|}{ Pearson's r correlations (NRMSE \%) } \\
\hline & NO, $n=127$ & $\mathrm{NO}_{2}, \mathbf{n}=127$ & ABS, $n=120$ & $\mathrm{PM}_{2.5} \neq \mathrm{n}=124$ \\
\hline LUR home§ & $0.49(7.6 \%) \dagger$ & $0.18(13 \%) \dagger$ & $-0.11(18 \%)$ & $0.07(17)$ \\
\hline LUR home+work & $0.55(6.9 \%) \dagger$ & $0.28(13 \%) \dagger$ & $-0.10(18 \%)$ & $0.10(17)$ \\
\hline Ambient monitors IDW monthly & $0.54(10 \%) \dagger$ & $0.05(13 \%)$ & $0.29 \dagger \dagger(18 \%) \dagger$ & $0.12(17)$ \\
\hline \multicolumn{5}{|l|}{$\begin{array}{l}\text { Subset analysis with }>65 \% \text { of total } \\
\text { sampling session at home }(n=61)\end{array}$} \\
\hline LUR home+work & $0.72(10 \%) \dagger$ & $0.26(15 \%) \dagger$ & $-0.14(24 \%)$ & $0.29(20 \%)$ \\
\hline Ambient monitors IDW monthly & $0.59(13 \%) \dagger$ & $0.06(15 \%)$ & $0.34(22 \%) \dagger$ & $0.10(21 \%)$ \\
\hline \multicolumn{5}{|l|}{$\begin{array}{l}\text { Subset analysis with } \leqslant 65 \% \text { of total } \\
\text { sampling session at home }(n=67)\end{array}$} \\
\hline LUR home & $0.18(14) \dagger$ & $0.14(20) \dagger$ & $-0.07(20)$ & $-0.07(16)$ \\
\hline LUR home+work & $0.31(14) \dagger$ & $0.31(20) \dagger$ & $-0.08(20)$ & $-0.08(16)$ \\
\hline
\end{tabular}

*The normalised RMSE is the root mean squared error divided by the range of the personal measurements. The RMSE represents the difference between values predicted by the exposure estimates and the observed values (personal measurements, in this case) and is defined as the square root of the mean squared error (measured units); the NRMSE is expressed as a percentage.

HIndicates that the Pearson $r$ correlation is significant at $p<0.05$; all others non-significant.

\$Personal measurements as $\mathrm{PM}_{2.2}$ were compared to ambient and LUR data measured as $\mathrm{PM}_{2.5}$.

§Land-use regression values for $\mathrm{NO}$ and $\mathrm{PM}_{25}$ are monthly averages, whereas absorbance and $\mathrm{NO}_{2}$ are annual averages.

-Personal absorbance was compared to ambient monitored $\mathrm{PM}_{2.5}$, since absorbance is not measured by the ambient monitoring network.

ABS, absorbance; IDW, inverse distance weighted; LUR, land-use regression.

\section{Evaluation of ambient monitors}

Ambient monitoring stations were relatively poor predictors of spatial variability in personal exposures for all measured pollutants except $\mathrm{NO}$, but good predictors of temporal variability. Mixed models (table 4) analyses show that most of the variance explained by the ambient monitor-based estimates was due to temporal correlations between subjects' personal measurements and outdoor concentrations (withinsubject variance component). In the case of $\mathrm{NO}$, we saw a small amount of between-subject (spatial) variance explained by ambient monitoring data. This is likely due to the dense network in the study region ( $\mathrm{n}=11$ monitors) and the relatively high spatial variability of this pollutant. Monitor-based $\mathrm{PM}_{2.5}$ estimates explained no spatial variability between subjects; all variance explained was temporal or within-subject. This is unsurprising given both the lower within-city variability of ambient $\mathrm{PM}_{2.5}{ }^{29}$ and the relatively few $(\mathrm{n}=6)$ monitoring stations available for interpolation.

Table 4 Models predicting personal measurements using outdoor ambient exposure estimates and controlling for repeated measures on subjects

\begin{tabular}{|c|c|c|c|c|c|}
\hline Model description (random and fixed effects) & \multicolumn{2}{|c|}{ Variance component (95\% confidence limits) } & \multicolumn{3}{|c|}{$\begin{array}{l}\% \text { Variance explained* (compared to } \\
\text { baseline) }\end{array}$} \\
\hline \multicolumn{6}{|l|}{ NO personal (dependent) } \\
\hline +LUR NO home & $0.214(0.156$ to 0.312$)$ & $0.180(0.107$ to 0.366$)$ & 36 & 4 & 24 \\
\hline +LUR NO home+work & $0.210(0.153$ to 0.306$)$ & 0.151 (0.086 to 0.327$)$ & 37 & 20 & 31 \\
\hline+ Ambient monitors IDW NO & $0.208(0.152$ to 0.304$)$ & $0.162(0.094$ to 0.343$)$ & 37 & 14 & 29 \\
\hline$+\mathrm{LUR} \mathrm{NO}_{2}$ home (annual) & $0.086(0.062$ to 0.125$)$ & $0.110(0.070$ to 0.199$)$ & 1 & 2 & 2 \\
\hline$+\mathrm{LUR} \mathrm{NO} \mathrm{N}_{2}$ home+work (annual) & $0.084(0.061$ to 0.122$)$ & $0.104(0.066$ to 0.190$)$ & 3 & 7 & 6 \\
\hline+ Ambient monitors IDW NO & - & & & & \\
\hline \multicolumn{6}{|l|}{ Absorbance personal (dependent) } \\
\hline Baseline (subject only) & 0.165 (0.118 to 0.246$)$ & $0.025(0.006$ to 1.341$)$ & & & \\
\hline Baseline (subject only) & $0.169(0.121$ to 0.251$)$ & $0.060(0.026$ to 0.251$)$ & & & \\
\hline+ LUR $\mathrm{PM}_{2.5}$ home & - & & & & \\
\hline +LUR PM 2.5 home+work & - & & & & \\
\hline +Ambient monitors IDW PM 2.5 & $0.154(0.110$ to 0.230$)$ & $0.075(0.036$ to 0.230$)$ & 9 & $(-)$ & \\
\hline
\end{tabular}

*The "\% variance explained" is simply a per cent change between the variance in the baseline model compared to one with an exposure estimate; "(-)" means that less variance was explained than by the baseline model.

$\dagger$ Per cent of variance explained from significant models (between- and within-subject) represents the amount of spatial and temporal variability, respectively, in personal measurements explained by the model effects. 
Main messages

- Air pollution concentrations as captured by ambient monitoring network measurements, and local scale concentrations differences, characterised in high resolution spatial models, both contribute to personal exposure to traffic-related air pollutants.

- Personal exposures to NO are predicted by land-use regression models, especially for those people spending most of their time at home.

- Incorporation of work or school address information, in addition to residential address, in exposure assessment improves the ability of models to estimate measured exposures.

- For NO, the land-use regression method can be used to estimate sub-annual averaged exposures and is useful for epidemiological studies where shorter exposure windows are of interest.

The inability of ambient monitoring methods to capture spatial variability between subjects has been shown in other (primarily cross-sectional) analyses comparing ambient and personal measurements. ${ }^{24}$ For example, a traffic-based index explained more variance in the personal measurements than ambient monitored $\mathrm{NO}_{2}{ }^{35}$ but less than ambient $\mathrm{PM}_{2.5}{ }^{23}$

We found low longitudinal correlations with ambient monitoring data when compared to other studies ${ }^{36-38}$ because we had few repeated samples (one to three per subject) and used the monthly average (to be consistent with the temporal component in the LUR model) of the ambient monitors. However, in sensitivity analyses, we recalculated ambient monitor concentrations averaged over the exact $48 \mathrm{~h}$ sampling session to clarify the impact of temporal trends on personal exposures. Moving to a more time-specific exposure window improved correlations between personal and ambient monitorbased concentrations for $\mathrm{NO}, \mathrm{PM}_{2.5}$ and absorbance but not for $\mathrm{NO}_{2}$. For example, a greater amount of within-subject variance in personal absorbance (6-42\%) was explained by ambient $\mathrm{PM}_{2.5}$ when a more refined time window was used.

\section{Comparing ambient versus LUR}

A unique feature of this study is the investigation of both ambient monitor-based and LUR estimates in comparison to personal measurements. The fact that both estimates were predictive of personal $\mathrm{NO}$ is especially interesting given that these two estimates show very different spatial characteristics. ${ }^{33}$ Hoek et $a l^{39}$ described three contributions to long-term average exposures: regional (ie, differences at $a \geqslant 100 \mathrm{~km}$ scale), urban (10 km scale) and local (1 km or less, modified by spatial proximity to traffic sources) and argued that contributions from each should be estimated separately and then combined to approximate long-term exposure. The results from this study showing that both local (represented by LUR estimates) and urban level components (represented by ambient monitoring concentrations) are contributors to personal measurements in this population lend further weight to this argument.

We note that measurements in this study were from a nonrandom (high educational attainment and non-smoking) sample of pregnant women. Sampling was weekday only and unevenly distributed across four seasons (but evenly distributed across heating and non-heating seasons). There were also differences in measurement methods (different samplers for ambient and personal sampling; personal measures of $\mathrm{PM}_{2.2}$ compared to monitoring network measures of $\mathrm{PM}_{2.5}$; variable badge performance for personal versus ambient sampling because of different

\section{Policy implications}

- Neighbourhood-scale air pollution is an important contributor to personal exposures, pointing to a need to focus on reductions in air pollutants at both the regional (background) and local (traffic) level.

- Exposures to ambient air pollution encountered at workplaces or schools are important contributors to air pollution exposure in addition to those encountered while at home.

face velocities) but we do not expect this to bias our results. The comparison between relatively few snapshot (48 h) measurements per person to exposure models designed for chronic exposure studies (LUR) suggests this is an imperfect evaluation of spatial differences in models designed for long-term exposure assessment. We acknowledge in particular that temporal scales are not consistent between the exposure measurements and estimates as a limitation of this analysis; however, it would be difficult to conduct month-long personal sampling to obtain the appropriate validation time scale for intermediate term exposure models.

\section{Importance of mobility}

There have been calls for increased use of mobility and timeactivity patterns to improve exposure assessment. ${ }^{40}$ When we analysed the subset of subjects spending more time at home on the sampling day, the (personal to home-only LUR) correlations were stronger with increasing time spent at home. This supports the use of LUR as a proxy for home exposure, especially for populations who spend a greater proportion of time at home. Including work locations as well as home locations improved our ability to estimate personal exposures.

Transit-time exposures can occur during peak pollution times on or near roadways, ${ }^{27}$ but in this study using GPS route data $(n=35)$ had little effect on exposure estimates compared to using home+work locations. However, we found the GPS technologies did not work well for the most mobile segment of our population. In univariate and multiple regression analyses (results not shown), time spent in motorised and non-motorised transit was not associated with personal exposures.

When considering exposure assessment methods to be used in future air pollution epidemiological studies, understanding the relevant time frame of the health effect of interest is important. For example, in studies of chronic exposure a LUR model could be combined with a yearly trend based on ambient data. The combination of LUR and monthly or yearly time trends presented in this paper is relatively novel and was developed for a study of birth outcomes which required an intermediatelength exposure window. For short-term exposures ambient monitor-based methods are likely adequate.

Acknowledgements: The authors gratefully acknowledge the study participants and their families, and the following members of the Border Air Quality Study team who contributed to this work: Katherine Rempel (sampling study assistance), Sarah Henderson (land-use regression model), Cornel Lencer and Lillian Tamburic (monitoring data) and Eleanor Setton (GIS assistance)

Funding: This research was funded by the British Columbia Centre for Disease Control, via an agreement with Health Canada as part of the U.S.-Canada Border Air Quality Strategy. Additional support was provided by the Center for Health and Environment Research at The University of British Columbia, funded by the Michael Smith Foundation for Health Research. Elizabeth Nethery was supported by a trainee award from the Michael Smith Foundation for Health Research.

Competing interests: None. 


\section{REFERENCES}

1. Sram RJ, Binkova B, Dejmek J, et al. Ambient air pollution and pregnancy outcomes: a review of the literature. Environ Health Perspect 2005:113(4):375-82.

2. Maisonet M, Correa A, Misra D, et al. A review of the literature on the effects of ambient air pollution on fetal growth. Environ Res 2004;95(1):106-15.

3. Huynh M, Woodruff TJ, Parker JD, et al. Relationships between air pollution and preterm birth in California. Paediatr Perinat Epidemiol 2006;20(6):454-61.

4. Leem JH, Kaplan BM, Shim YK, et al. Exposures to air pollutants during pregnancy and preterm delivery. Environ Health Perspect 2006;114(6):905-10.

5. Wilhelm M, Ritz B. Residential proximity to traffic and adverse birth outcomes in Los Angeles county, California, 1994-1996. Environ Health Perspect 2003;111(2):207-16.

6. Jedrychowski W, Bendkowska I, Flak E, et al. Estimated risk for altered fetal growth resulting from exposure to fine particles during pregnancy: an epidemiologic prospective cohort study in Poland. Environ Health Perspect 2004:112(14):1398-402.

7. Perera FP, Rauh V, Whyatt RM, et al. Molecular evidence of an interaction between prenatal environmental exposures and birth outcomes in a multiethnic population. Environ Health Perspect 2004;112(5):626-30.

8. Ritz B, Yu F. The effect of ambient carbon monoxide on low birth weight among children born in southern California between 1989 and 1993. Environ Health Perspect 1999:107(1):17-25

9. Hoek G, Meliefste K, Cyrys J, et al. Spatial variability of fine particle concentrations in three European areas. Atmos Environ 2002;36(25):4077-88.

10. Lewne M, Cyrys J, Meliefste K, et al. Spatial variation in nitrogen dioxide in three European areas. Sci Total Environ 2004;332(1-3):217-30.

11. Van der Zee SC, Hoek G. Harssema $H$, et al. Characterization of particulate air pollution in urban and non-urban areas in the Netherlands. Atmos Environ 1998:32(21):3717-29.

12. Zhu YF, Hinds WC, Kim S, et al. Study of ultrafine particles near a major highway with heavy-duty diesel traffic. Atmos Environ 2002;36(27):4323-35.

13. Miller KA, Siscovick DS, Sheppard L, et al. Long-term exposure to air pollution and incidence of cardiovascular events in women. N Engl J Med 2007;356(5):447-58.

14. Jerrett $\mathbf{M}$, Burnett RT, Ma R, et al. Spatial analysis of air pollution and mortality in Los Angeles. Epidemiology 2005:16(6):727-36.

15. Brunekreef $\mathbf{B}$, Janssen NA, de Hartog J, et al. Air pollution from truck traffic and lung function in children living near motorways. Epidemiology 1997;8(3):298-303.

16. Janssen NA, Brunekreef $B$, van Vliet $P$, et al. The relationship between air pollution from heavy traffic and allergic sensitization, bronchial hyperresponsiveness, and respiratory symptoms in Dutch schoolchildren. Environ Health Perspect 2003:111(12):1512-18.

17. Morgenstern V, Zutavern A, Cyrys J, et al. Respiratory health and individual estimated exposure to traffic-related air pollutants in a cohort of young children. Occup Environ Med 2007:64(1):8-16.

18. Brauer $\mathbf{M}$, Hoek $G$, van Vliet $P$, et al. Estimating long-term average particulate air pollution concentrations: application of traffic indicators and geographic information systems. Epidemiology 2003:14(2):228-39.

19. Briggs DJ, de Hoogh C, Gulliver J, et al. A regression-based method for mapping traffic-related air pollution: application and testing in four contrasting urban environments. Sci Total Environ 2000;253(1-3):151-67.

20. Van Roosbroeck S, Wichmann J, Janssen NA, et al. Long-term personal exposure to traffic-related air pollution among school children, a validation study. Sci Total Environ 2006;368(2-3):565-73.

21. Rijnders $\mathbf{E}$, Janssen NA, van Vliet PH, et al. Personal and outdoor nitrogen dioxide concentrations in relation to degree of urbanization and traffic density. Environ Health Perspect 2001;109(Suppl 3):411-17.
22. Nerriere E, Zmirou-Navier D, Blanchard 0, et al. Can we use fixed ambient air monitors to estimate population long-term exposure to air pollutants? The case of spatial variability in the Genotox ER study. Environ Res 2005;97(1):32-42.

23. Gauvin S, Reungoat $P$, Cassadou $S$, et al. Contribution of indoor and outdoor environments to PM2.5 personal exposure of children-VESTA study. Sci Total Environ 2002;297(1-3):175-81.

24. Gauvin S, Le Moullec $Y$, Bremont F, et al. Relationships between nitrogen dioxide personal exposure and ambient air monitoring measurements among children in three French metropolitan areas: VESTA study. Arch Environ Health 2001; $\mathbf{5 6}(4): 336-41$

25. Leech JA, Nelson WC, Burnett RT, et al. It's about time: a comparison of Canadian and American time-activity patterns. J Expo Anal Environ Epidemiol 2002:12(6):427-32.

26. Marshall JD, Granvold PW, Hoats AS, et al. Inhalation intake of ambient air pollution in California's South Coast Air Basin. Atmos Environ 2006/7:40(23):4381-92.

27. Gulliver J, Briggs DJ. Time-space modeling of journey-time exposure to trafficrelated air pollution using GIS. Environ Res 2005:97(1):10-25.

28. Henderson SB, Beckerman B, Jerrett M, et al. Application of land use regression to estimate long-term concentrations of traffic-related nitrogen oxides and fine particulate matter. Environ Sci Technol 2007:41(7):2422-8.

29. Ebelt ST, Petkau AJ, Vedal S, et al. Exposure of chronic obstructive pulmonary disease patients to particulate matter: relationships between personal and ambient air concentrations. J Air Waste Manag Assoc 2000;50(7):1081-94.

30. Pekkanen J, Timonen K, Tiittanen P, et al. ULTRA. Exposure and risk assessment for fine and ultrafine particles in ambient air. Study manual and data book. Kuopio, Finland: KTL, 2000. Available at http://www.ktl.fi/ultra/\#STUDY\%20MANUAL (accessed 10 January 2008).

31. Setton EM, Hystad PW, Keller CP. Opportunities for using spatial property assessment data in air pollution exposure assessments. Int $J$ Health Geogr 2005;4:26.

32. GVRD/FVRD Policy and Planning Department. Lower Fraser Valley ambient air quality report 2005. BC, Canada: Greater Vancouver Regional District/Fraser Valley Regional District, 2005.

33. Marshall JD, Nethery E, Brauer M. Within-urban variability in ambient air pollution: comparison of estimation methods. Atmos Environ 2007:42:1359-69.

34. Hitchins J, Morawska L, Gilbert D, et al. Dispersion of particles from vehicle emissions around high- and low-rise buildings. Indoor Air 2002:12(1):64-71.

35. Reungoat $\mathbf{P}$, Chiron $\mathrm{M}$, Gauvin $\mathrm{S}$, et al. Assessment of exposure to traffic pollution using the ExTra index: study of validation. Environ Res 2003;93(1):67-78.

36. Janssen NA, Lanki T, Hoek G, et al. Associations between ambient, personal, and indoor exposure to fine particulate matter constituents in Dutch and Finnish panels of cardiovascular patients. Occup Environ Med 2005;62(12):868-77.

37. Sarnat JA, Brown KW, Schwartz J, et al. Ambient gas concentrations and personal particulate matter exposures: implications for studying the health effects of particles. Epidemiology 2005;16(3):385-95

38. Janssen NA, Hoek G, Brunekreef B, et al. Personal sampling of particles in adults: relation among personal, indoor, and outdoor air concentrations. Am J Epidemiol 1998;147(6):537-47.

39. Hoek G, Fischer $P$, Van Den Brandt $P$, et al. Estimation of long-term average exposure to outdoor air pollution for a cohort study on mortality. J Expo Anal Environ Epidemiol 2001;11(6):459-69.

40. Briggs D. The role of GIS: coping with space (and time) in air pollution exposure assessment. J Toxicol Environ Health A 2005:68(13-14):1243-61. 